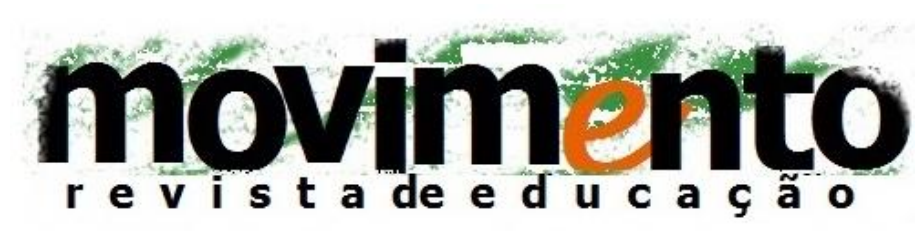

faculdade de educação - programa de pós-graduação em educação

universidade federal fluminense

issn 2359-3296

ano 3 número 5 - 2016

\title{
REGINA LEITE GARCIA, PRESENTE! 1
}

Edwiges Zaccur2

É uma responsabilidade e uma honra participar, como representante do Grupalfa, da justíssima homenagem que o Programa de Pós-Graduação da UFF presta a Regina Leite Garcia. Poderia me valer do tempo passado para alinhar uma série imensa de contribuições desta educadora ímpar à nossa universidade, à educação brasileira e latino-americana. Mas o que é o passado senão uma sucessão de presentes que ecoam e fazem diferença, sobretudo, quando se trata de Regina Leite Garcia. Opto, assim, por fazer ecoar muitos presentes outros, encontros e desencontros, palavras e contra-palavras. E, sobretudo, trocas e aprendizagens.

Como ponto de partida, ajusto o foco na jovem professora Regina em início da carreira docente: pequena, aparentemente frágil e contraditoriamente tão forte e determinada, tomando diariamente o trem em direção ao Mendanha. Recupero ecos de sua experiência na zona oeste do Rio de Janeiro, contada e recontada. Sondo palavras ditas, ouvidas e refletidas. O pouco rendimento das crianças antes do recreio; a discussão reunindo não apenas professoras, mas todos os profissionais da escola; a solução trazida pela merendeira: servir café com leite e biscoito às crianças antes do início das aulas. Simples assim... Entre outros

\footnotetext{
1 Texto apresentado pela autora na seção de homenagem em memória de Regina Leite Garcia na Faculdade de Educação da Universidade Federal Fluminense.

2 Doutora em Educação pela Universidade Federal Fluminense/Université Paris VII. Professora da Faculdade de Educação da Universidade Federal Fluminense. Membro do Grupalfa-UFF.
} 


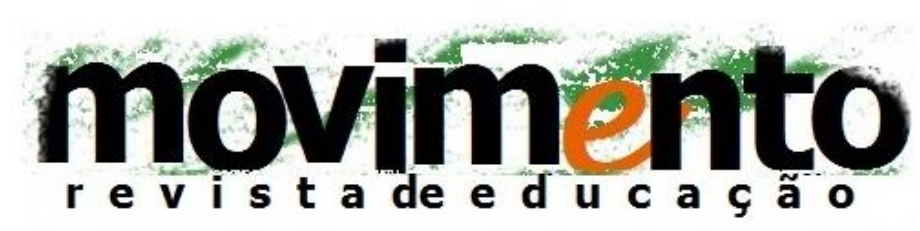

faculdade de educação - programa de pós-graduação em educação

universidade federal fluminense

issn 2359-3296

ano 3 número 5 - 2016

sentidos possíveis, é possível dizer que ali nasce tanto a educadora como a pesquisadora. Não seria aquela uma experiência que tomba, como diria Jorge Larrosa, e que se refrata em quaisquer outros espaços?

Destacamos sete dos muitos espectros em que aquela experiência do Mendanha se refrata: O primeiro deles não poderia deixar de ser a construção coletiva do conhecimento. Registro a minha primeira surpresa ao chegar a sua turma do mestrado, por não haver propriamente aula, mas diálogos, reflexões, palavras e contra palavras, em permanente interação. Nesse movimento, puxam-se fios do texto do autor em discussão, para refletir com ele e contra ele, para chamá-lo a nos ajudar a ver com outros olhos as nossas próprias experiências. Foco o rosto de Regina, como num filme que a memória não apaga: a sua escuta atenta, um aval; o brilho nos olhos, a descoberta de algo novo. Anúncios de pesquisas e teses, tendo as discussões nos encontros como ponto de partida.

Aprendemos que estar ou não estar presente a cada encontro seria interferir no grupo, falar ou calar-se também. Palavras e contra-palavras provocando o pensamento em permanente busca, como que garimpando questões dentro de questões. Indagando sempre, porque, bakhtinianamente, o diálogo não pode cessar.

Como segundo espectro, destaco a formação de nosso grupo de pesquisa: o Grupalfa. Um grupo não é apenas um conjunto de pessoas que se reúnem em um determinado tempo e lugar, tendo um objetivo em comum. Um grupo, nesse caso, constitui um projeto-mãe que ativa outros projetos e transforma a vida dos seus integrantes. Podemos ouvir de novo a voz de Regina a respeito do 


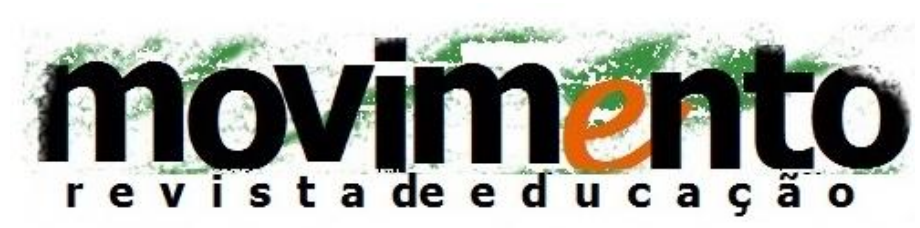

faculdade de educação - programa de pós-graduação em educação

universidade federal fluminense

issn 2359-3296

ano 3 número 5 - 2016

GRUPALFA em entrevista concedida em Portugal e publicada em A Página da Educação, de julho de 2001.

\begin{abstract}
Esse grupo iniciou-se com a minha entrada na Universidade Federal Fluminense. Até lá, fui professora primária, orientadora educacional, tendo trabalhado nos diferentes níveis educacionais das escolas do Rio de Janeiro. Nessa altura levava comigo não só um forte compromisso com a escola primária, mas uma vivência política que me fazia compreender que tudo o que se faz na escola tem um carácter político, nada é neutro. Trazia também uma longa história de acção e reflexão sobre a escola destinada às crianças das classes populares, e aquele que é o grande "nó", digamos assim, que é a alfabetização dos alunos das classes populares. A minha tese de doutoramento foi dedicada a este tema, que eu considerava "ainda um desafio". Quando entrei na universidade transformei a minha tese de doutoramento num projecto de pesquisa, para o qual convidei três alunas minhas. Entre nós existe uma preocupação e um comprometimento comum pela alfabetização dos alunos das classes populares [...].
\end{abstract}

Rapidamente, ao núcleo inicial, agregam-se outras professoras, sempre marcadas pela preocupação e comprometimento comum com a alfabetização dos alunos das classes populares. Um grupo de professoras pesquisadoras, vivendo a construção de uma práxis, sempre problematizando a escola que temos e a que alimenta a nossa utopia. Dando consequência a tantas questões, Regina aciona a criação do curso de pós-graduação Alfabetização das crianças classes populares. Esse mesmo que se renova e, sob a coordenação de Carmen Perez, acaba de concluir o processo de seleção para a sua $11^{\underline{a}}$ turma, formada por 40 aprovados dentre os 137 inscritos. A turma Regina Leite Garcia.

Como um terceiro espectro da experiência original que se disseminou, está a preocupação de Regina Leite Garcia em fazer escola, formando quadros potentes. Entre orientandos seus, graduandos, pós-graduandos, mestrando e doutorandos de Regina temos perto de cem. Se somarmos a esse número o total de monografias, dissertações e teses das quais seus ex-orientandos se tornaram orientadores, o número está em torno de mil. Mas se acrescentarmos aí as 


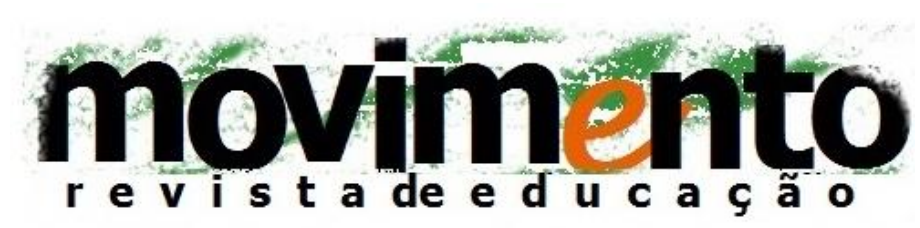

faculdade de educação - programa de pós-graduação em educação

universidade federal fluminense

issn 2359-3296

ano 3 número 5 - 2016

formações continuadas e seminários coordenados por Regina Leite Garcia pelo Brasil afora, América Latina e Portugal, esse número se multiplica exponencialmente.

E, sobretudo, mais do que pensarmos quantitativamente há que se pensar qualitativamente. Só em universidades do chamado Grande Rio somos mais de 10 professoras doutoras, cada uma com seu jeito peculiar de ser potente. Isto é, capaz de enfrentar desafios, superar dificuldades, ir à luta, tornando-se, por sua vez, formadora de novos quadros. Cada uma de nós ouviu em algum momento crucial de sua vida, a voz de poderosa de Regina Leite Garcia a nos empoderar e impelir à frente: "VOCÊ PODE". Uma verdadeira profecia realizável a expandir os nossos horizontes.

Uma quarta refração: sua luta contra a hegemonia. Faz toda diferença manter acesas as tensões, fugir das zonas de conforto, inquietar e inquietar-se no conflito, pelo conflito e a partir do conflito. É necessário estar em alerta, sentarse na ponta da cadeira, desequilibrando-se, reequilibrado-se para de novo se desequilibrar. Com Regina começamos a ler Gramsci que nos alerta em Os jornais e os operários:

Todos os dias, [...] os jornais burgueses apresentam os fatos, mesmo os mais simples, de modo a favorecer a classe burguesa e a política burguesa, com prejuízo da política e da classe operária. [...] E não falemos daqueles casos em que o jornal burguês ou cala, ou deturpa, ou falsifica para enganar, iludir e manter na ignorância o público trabalhador.

Mais que nunca, portanto, é preciso lutar. Não para conquistar a hegemonia e se transformar em mais do mesmo, mas para manter a vigília permanente. 


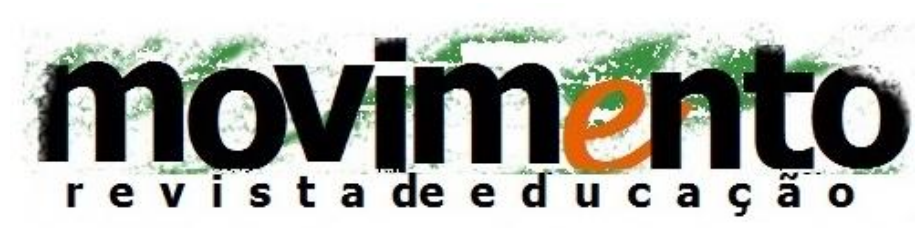

faculdade de educação - programa de pós-graduação em educação

universidade federal fluminense

issn 2359-3296

ano 3 número 5 - 2016

Uma quinta refração: a acolhida a toda e qualquer diferença. Se querem saber onde está a riqueza, olhem em volta: ela está na diferença. Vamos escutar de novo as palavras de Regina:

Só se sentirá livre para aceitar legitimamente todas as suas dimensões quem aceita o outro enquanto legítimo outro, lembrando a origem comum no todo social. Tratando-se de uma trama interdependente de relações sociais, não aceitar o outro impede a aceitação de si mesmo. Em diálogo com Maturana, essa concepção de outridade se abre também à escola. Eu defendo que a escola deveria ser um espaço de expressão e de respeito das diferenças. E se assim for ela é um espaço de pluralidade cultural, sendo, portanto, um espaço de confronto dos diversos olhares para a sociedade. É, portanto, um espaço de riqueza e de pluricultura, e não de monocultura. (A página, junho de 2001).

O que significa dizer um redondo não a tudo que homogeneíza sob a égide do pensamento único, europeu, branco, cristão, machista.

Ainda uma sexta refração: a aposta de Regina nos saberes dos sujeitos da escola, insistindo na leitura e releitura de Gramsci e Paulo Freire, seus interlocutores frequentes. Do primeiro, um repetido alerta sobre a primazia do pensamento que a todos irmana: "os que não sabem pensam". Do segundo, a premissa de que todos são sujeitos de cultura com modos próprios de pensar e conhecer. O artigo compartilhado com Victor Valla e que deu título ao Caderno Cedes, A fala dos excluídos, nos permite escutá-los de novo:

Nem os representantes do poder constituído, nem tampouco a Academia, as ONGs, os partidos políticos têm conseguido "ler" as falas dos grupos populares no sentido que eles dão a suas próprias. Ainda que comprometidos com suas lutas, frequentemente, "interpretam as falas populares" a partir de sua visão etnocêntrica, que os leva a avaliar as falas dos outros como fragmentos de um discurso desarticulado sincrético e pouco coerente.

Por fim e não por último, uma sétima refração: a disseminação de Regina Leite Garcia em palavras e textos, atos e pura energia. Palavras que estão vivas e 


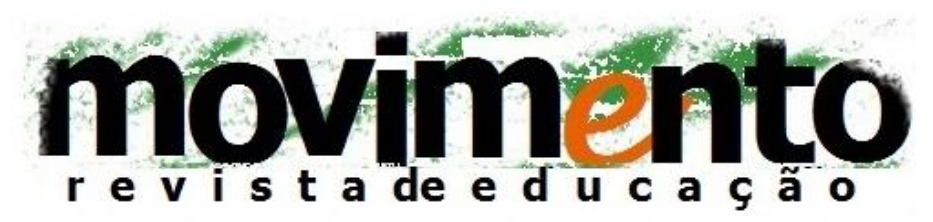

faculdade de educação - programa de pós-graduação em educação

universidade federal fluminense issn 2359-3296

ano 3 número 5 - 2016

presentes em nós, que seguirão conosco onde quer que possamos ir, dentro e fora do Brasil. Palavras dela que se misturam às nossas, a tal ponto que não sabemos onde começam as nossas ou as delas. Energia viva que não se dissipa, enquanto seus livros e suas palavras puderem ecoar.

Alinhamos sete refrações. Sete é um número mágico composto de 3 , número simbolicamente representado no plano superior, e do número 4, que diz dos elementos vitais no plano inferior e humano: terra, água, ar e fogo. Sete são também as cores do arco-íris. Justo nesse momento de tormenta em que estamos vivendo sob um simulacro de democracia. Mais do que nunca é preciso regar, com a esperança combativa, a luta contra um governo ilegítimo que investe contra nossas conquistas. Mais do que nunca é preciso manter viva a esperança, a luta de Regina Leite Garcia e nossa pela escola pública, pela universidade pública, nesta república em que, se nada fizermos, será cada vez menos res-pública.

Por tudo isso, esse texto é aberto e fechado com as palavras pronunciadas por Cunca Bocayuva no dia 25 de julho de 2016: "Regina Leite Garcia, presente! " 